\title{
Chloral hydrate-dependent reduction in the peptidoglycan-induced inflammatory macrophage response is associated with lower expression levels of toll-like receptor 2
}

\author{
QINGJUN PAN $^{1}$, YUAN LIU $^{2}$, XUEZHI ZHU ${ }^{3}$ and HUAFENG LIU ${ }^{1}$ \\ ${ }^{1}$ Institute of Nephrology, Affiliated Hospital of Guangdong Medical College, Zhangjiang, Guangdong 524001; \\ ${ }^{2}$ Department of Paediatrics and Adolescent Medicine, Li Ka Shing Faculty of Medicine, \\ University of Hong Kong, Hong Kong, SAR 999077; ${ }^{3}$ Guangdong Yuehai Feed Group Co. Ltd., \\ Zhangjiang, Guangdong 524001, P.R. China
}

Received September 25, 2013; Accepted February 21, 2014

DOI: $10.3892 /$ etm.2014.1587

\begin{abstract}
The aim of this study was to investigate the effect and mechanism of action of chloral hydrate on the peptidoglycan (PGN)-induced inflammatory macrophage response. The effect of chloral hydrate on the production of tumor necrosis factor $\alpha$ (TNF- $\alpha$ ) and interleukin-6 (IL-6) by murine peritoneal macrophages with PGN-stimulation was investigated. In addition, RAW264.7 cells transfected with a nuclear factor- $\kappa \mathrm{B}(\mathrm{NF}-\kappa \mathrm{B})$ luciferase reporter plasmid stimulated by PGN were used to study the effect of chloral hydrate on the levels $\mathrm{NF}-\kappa \mathrm{B}$ activity. Flow cytometry and western blotting were performed to investigate the expression levels of toll-like receptor 2 (TLR2) in the treated RAW264.7 cells. It was identified that chloral hydrate reduced the levels of IL- 6 and TNF- $\alpha$ produced by the peritoneal macrophages stimulated with PGN. The levels of NF- $\kappa$ B activity of the RAW264.7 cells stimulated by PGN decreased following treatment with chloral hydrate, which was associated with a reduction in the expression levels of TLR2 and reduced levels of TLR2 signal transduction. These data demonstrate that chloral hydrate reduced the magnitude of the PGN-induced inflammatory macrophage response associated with lower expression levels of TLR2.
\end{abstract}

Correspondence to: Professor Huafeng Liu, Institute of Nephrology, Affiliated Hospital of Guangdong Medical College, 57 Renmin Avenue (South), Zhangjiang, Guangdong 524001, P.R. China

E-mail: hf_liu@263.com

Key words: chloral hydrate, peptidoglycan, inflammatory response, macrophage, toll-like receptor 2

\section{Introduction}

Chloral hydrate is a well-known sedative and anesthetic that is used in pediatric procedures, including echocardiograms and magnetic resonance imaging (1-5), and in animal experiments (6-9). Its safety and pharmacological mechanisms in clinical practice have been emphasized (10-12)

In a previous study, it was demonstrated that therapeutic concentrations of chloral hydrate delayed and reduced the magnitude of the inflammatory response and improved the survival rate of mice following the induction of liver injury with lipopolysaccharide and D-galactosamine. This altered inflammatory response was associated with the inhibitory effects of chloral hydrate on nuclear factor- $\kappa \mathrm{B}(\mathrm{NF}-\kappa \mathrm{B})$ activity and the levels of serum proinflammatory cytokines induced by lipopolysaccharide (13).

Peptidoglycan (PGN) is a common and conserved component of the cell walls of Gram-positive (G+) bacteria, including Staphylococcus aureus, and has been used as a toll-like receptor 2 (TLR2)-specific ligand (14). It has been reported that PGN is detected in the blood of $80 \%$ of patients with serious bacterial infections (15). The mononuclear phagocyte system plays a crucial role against infection in the innate immune response, and murine macrophages are an important model for studying infection. Following stimulation with PGN, NK- $\kappa \mathrm{B}$ becomes activated and macrophages release large quantities of the proinflammatory cytokines IL- 6 and TNF- $\alpha$. Simultaneously, the levels of TLR2 expression become upregulated $(16,17)$. Activation of a murine macrophage cell line (RAW264.7) by PGN is mediated through the TLR2 signaling cascade, which involves the activation of a number of kinases, including p38 mitogen-associated protein kinase (MAPK), extracellular signal-regulated kinase (ERK) $1 / 2$, inhibitor of NF- $\kappa \mathrm{B} \alpha(\mathrm{I} \kappa \mathrm{B} \alpha)$ and Akt $(18,19)$.

In the present study, the effect of chloral hydrate on the production of the proinflammatory cytokines and the activity of NF- $\mathrm{KB}$ in PGN-stimulated murine peritoneal macrophages and RAW264.7, respectively, was investigated. The study 
includes an exploration of the mechanisms and an investigation of the effects of chloral hydrate treatment on the expression levels of TLR2 and TLR2 signal transduction in murine peritoneal macrophages and RAW264.7 cells stimulated with PGN.

\section{Materials and methods}

Reagents. PGN (S. aureus, strain DSM346), chloral hydrate (cat. no. 302-17-0) and trypsin-EDTA solution (10X; cat. no. T4174) were purchased from Sigma-Aldrich (St. Louis, MO, USA). Iscove's modified Dulbecco's medium (IMDM) and fetal bovine serum (FBS) were purchased from Gibco (Grand Island, NY, USA). The TNF- $\alpha$ and IL-6 ELISA kits were obtained from R\&D Systems, Inc. (Minneapolis, MN, USA). The fluorescein isothiocyanate (FITC)-conjugated anti-mouse TLR2 antibody (clone TL2.5), FITC-conjugated mouse IgG1 (isotype control), anti-mouse TLR2 antibody (clone TL2.5), horseradish peroxidase (HRP)-conjugated goat anti-mouse secondary antibody and Cell Staining Buffer were purchased from BioLegend, Inc. (San Diego, CA, USA). The antibodies against p38 MAPK, phospho-p38 MAPK, ERK 1/2, phospho-ERK1/2, IкB $\alpha$, phospho-IкB $\alpha$, Akt, phospho-Akt and $\beta$-actin were obtained from Cell Signaling Technology, Inc. (Waltham, MA, USA). The $\mathrm{NF}-\kappa \mathrm{B}$-luciferase and $\beta$-galactosidase reporter vectors and the dual luciferase reporter assay system were obtained from Promega Corporation (Madison, WI, USA). The Immobilon-P membrane was obtained from Millipore UK Ltd. (Watford, UK) and the enhanced chemiluminescence (ECL) kit was purchased from Amersham Life Science Ltd. (Little Chalfont, UK).

Effects of chloral hydrate on proinflammatory cytokine production by murine peritoneal macrophages stimulated with PGN. The separation and cultivation of mouse peritoneal macrophages were performed as previously described (20). The Institutional Review Board of the Affiliated Hospital of Guangdong Medical College (Zhangjiang, China) approved the removal of the macrophages from the s ix-week-old BALB/c mice were purchased from Experimental Animal Center of Southern Medical University in the present study. The cells were seeded at a density of $1 \times 10^{5}$ cells/well in 12 -well plates in IMDM supplemented with $5 \%$ heat-inactivated FBS in a humidified $5 \% \mathrm{CO}_{2}$ and air incubator at $37^{\circ} \mathrm{C}$. The supernatants were collected at 6,12 and $24 \mathrm{~h}$ following stimulation with PGN $(1 \mu \mathrm{g} / \mathrm{ml})$ or PGN $(1 \mu \mathrm{g} / \mathrm{ml})$ plus chloral hydrate $(0.25$ and $1 \mathrm{mg} / \mathrm{ml})$ and saline-treated controls. The supernatants were then stored at $-80^{\circ} \mathrm{C}$ prior to the measurement of the levels of TNF- $\alpha$ and IL- 6 using the corresponding ELISA kits according to the manufacturer's instructions.

Effects of chloral hydrate on the levels $N F-\kappa B$ activity in $P G N$-stimulated RAW264.7 cells transfected with a NF- $\kappa B$ luciferase reporter plasmid. The RAW264.7 cells were purchased from the Type Culture Collection of the Chinese Academy of Sciences (Shanghai, China) and cultured in IMDM (5\% FBS) and maintained at $37^{\circ} \mathrm{C}$ in $5 \% \mathrm{CO}_{2}$. The cells were seeded in $25-\mathrm{mm}$ dishes at a density of $1 \times 10^{6}$ cells per well. These cells were harvested with $0.25 \mathrm{~g} / 1$ trypsin-EDTA $48 \mathrm{~h}$ later, and $5 \times 10^{6}$ RAW264.7 cells were transiently transfected with $\mathrm{NF}-\kappa \mathrm{B}$-luciferase $(5 \mu \mathrm{g})$ and $\beta$-galactosidase reporter $(5 \mu \mathrm{g})$ vectors (for normalization of the efficiency of the transfection) in a volume of $400 \mu 1$ by electroporation at $250 \mathrm{~V}$, $960 \mu \mathrm{F}$ capacitance pulse as previously described (21). The cells were subsequently washed once in IMDM and then split into 50 wells (100 $\mu \mathrm{l} /$ well) and cultured for $24 \mathrm{~h}$ in IMDM (5\% FBS), prior to stimulation with PGN $(1 \mu \mathrm{g} / \mathrm{ml})$ for 6 or $12 \mathrm{~h}$ in the presence or absence of chloral hydrate $(0.25$ or $1 \mathrm{mg} / \mathrm{ml})$. For the luciferase activity assays, the transfected RAW264.7 cells were stimulated for 6 or $12 \mathrm{~h}$ and subsequently harvested and lysed, and the luciferase activity in the extracts was assayed with the dual luciferase reporter assay system according to the manufacturer's instructions. The luciferase activity of the cell extracts is expressed as the fold of luciferase-induction over that of a saline-treated control.

Effects of chloral hydrate on PGN-induced upregulation of TLR2 expression levels in RAW264.7 cells. Flow cytometry was performed to investigate the levels of TLR 2 expression in the RAW264.7 cells. The RAW 264.7 cells were cultured in $\operatorname{IMDM}(5 \% \mathrm{FBS})$ for $12 \mathrm{~h}$ with PGN $(1 \mu \mathrm{g} / \mathrm{ml})$ in the presence or absence of chloral hydrate $(0.25 \mathrm{mg} / \mathrm{ml})$. After harvesting, the cells were incubated with FITC-conjugated anti-mouse-TLR2 $(1 \mu \mathrm{g})$ for 30 minutes at room temperature without permeabilization. As the isotype control, FITC-conjugated mouse IgG1 was used to detect nonspecific staining. The cells were washed twice with Cell Staining Buffer. A six-parameter flow cytometer (FACScan; BD Biosciences, San Jose, CA, USA) was used in the data acquisition. The analysis of the acquired data was performed using CellQuest software (BD Biosciences Immunocytometry Systems, San Jose, CA, USA). The mean channel fluorescence intensity (MFI) derived from the fluorescence histogram was used to study the levels of TLR2 expression. The MFI was calculated as a ratio and recorded as the MFI of the TLR2 antibody divided by the MFI of a normal (saline) control.

The TLR2 expression levels in the extracts from the RAW264.7 cells stimulated with PGN (1 $\mu \mathrm{g} / \mathrm{ml})$ for $12 \mathrm{~h}$ in the presence or absence of chloral hydrate $(0.25 \mathrm{mg} / \mathrm{ml})$ were semi-quantitatively analyzed by western blotting using the anti-mouse TLR2 antibody (clone TL2.5). The extracts from the RAW264.7 cells were analyzed by sodium dodecyl sulfate-polyacrylamide gel electrophoresis. The immunoblotting was performed by a standard western blotting procedure onto the Immobilon membrane. HRP-conjugated goat anti-mouse secondary antibody followed by ECL was used for the detection of the TLR2 signal. The semi-quantitative analysis of the extracts from the RAW264.7 cells was conducted using BandScan software, version 5.0 (Glyko Inc., Novato, CA, USA).

Effects of chloral hydrate on PGN-induced TLR2 signal transduction in RAW264.7 cells. The TLR2 expression levels in the extracts from the RAW264.7 cells stimulated with PGN $(1 \mu \mathrm{g} / \mathrm{ml})$ for $12 \mathrm{~h}$ in the presence or absence of chloral hydrate $(0.25 \mathrm{mg} / \mathrm{ml})$ were semi-quantitatively analyzed by western blotting using antibodies against MAPK, phospho-p38 MAPK,

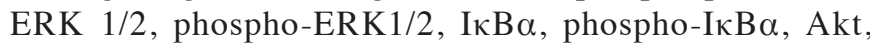
phospho-Akt and $\beta$-actin. Western blot analysis and detection 
A

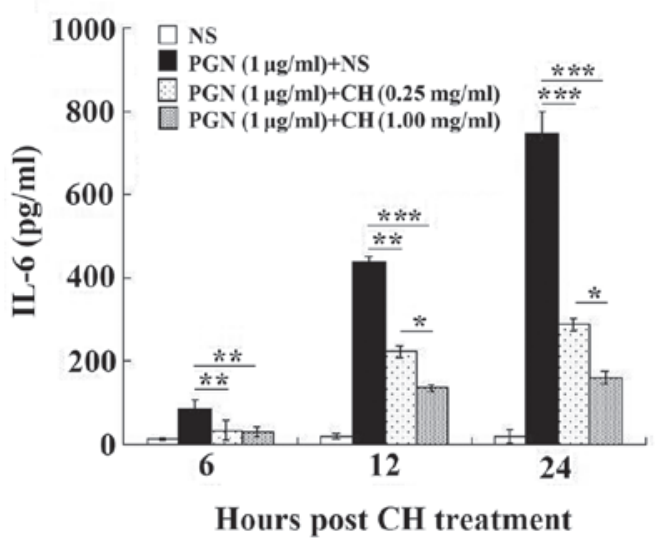

B

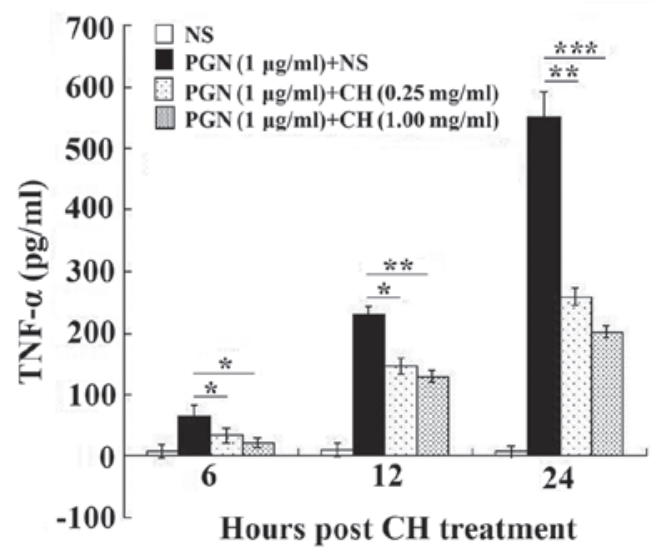

Figure 1. Chloral hydrate $(\mathrm{CH})$ treatment decreased the levels of IL-6 and TNF- $\alpha$ production by peritoneal macrophages following PGN stimulation. The effects of chloral hydrate $(0.25$ and $1 \mathrm{mg} / \mathrm{ml})$ on the levels of (A) IL-6 and (B) TNF- $\alpha$ produced by peritoneal macrophages (1x10 ${ }^{6}$ cell/well) following PGN stimulation for 6,12 and 24 h. The data are expressed as the mean \pm SD of three independent experiments. ${ }^{*} \mathrm{P}<0.05$, ${ }^{* *} \mathrm{P}<0.01$ and ${ }^{* * *} \mathrm{P}<0.001$. IL-6, interleukin-6; TNF- $\alpha$, tumor necrosis factor $\alpha$; NS, normal saline; PGN, peptidoglycan.

were performed as previously described in this study. The semi-quantitative analysis of the extracts from the RAW264.7 cells was conducted using BandScan software.

Statistical analysis. The data are presented as the mean \pm standard deviation, and the statistical analysis was performed with SPSS statistical software, version 15.0 (SPSS, Inc., Chicago, IL, USA). The statistical significance between the two groups was determined by the unpaired Student's t-test. A value of $\mathrm{P}<0.05$ was considered to indicate a statistically significant difference.

\section{Results}

Chloral hydrate treatment reduces the levels of IL-6 and TNF- $\alpha$ produced by $P G N$-stimulated peritoneal macrophages. The results showed that the levels of IL-6 (Fig. 1A) and TNF- $\alpha$ (Fig. 1B) production increased sharply post-stimulation with PGN $(1 \mu \mathrm{g} / \mathrm{ml})$ for 6,12 and $24 \mathrm{~h}$, compared with those of the untreated cells, and decreased significantly following the chloral hydrate treatment $(0.25$ and $1 \mathrm{mg} / \mathrm{ml})$, compared with those of the cells treated with $\mathrm{PGN}$ alone (all $\mathrm{P}<0.01)$. In addition, the higher concentration of chloral hydrate $(1 \mathrm{mg} / \mathrm{ml})$ significantly reduced the levels of IL- 6 production following stimulation with PGN $(1 \mu \mathrm{g} / \mathrm{ml})$ for 12 and $24 \mathrm{~h}$ compared with those of the cells treated with the lower concentration of chloral hydrate $(0.25 \mathrm{mg} / \mathrm{ml}$; all $\mathrm{P}<0.05$; Fig. $1 \mathrm{~A})$.

Chloral hydrate-treatment reduces the levels of $N F-\kappa B$ activity in PGN-stimulated RAW264.7 cells. The levels of luciferase activities in the transfected RAW264.7 cells were measured at 6 and $12 \mathrm{~h}$ after PGN stimulation (Fig. 2). The results are presented as a fold of induction over the values obtained in the normal saline groups. As shown in Fig. 2, 1.5- and 3.5-fold increases in the luciferase activity were observed following the PGN stimulation for $6 \mathrm{~h}$ and $12 \mathrm{~h}$, respectively, compared with those of the untreated cells. The effect of PGN-stimulation was significantly reduced by the chloral hydrate treatment $(0.25$ and $1 \mathrm{mg} / \mathrm{ml}$; all $\mathrm{P}<0.01)$. A higher concentration of chloral hydrate $(1 \mathrm{mg} / \mathrm{ml})$ led to

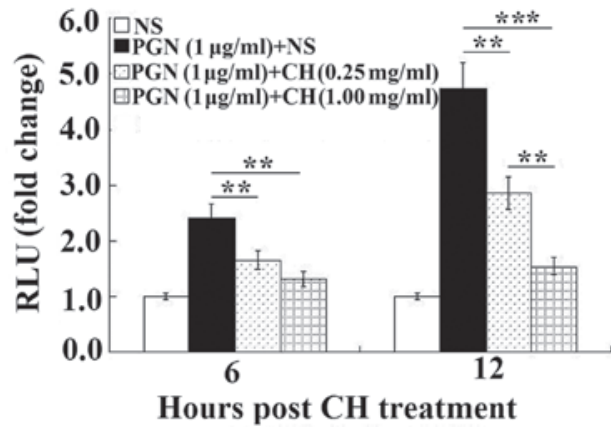

Figure 2. Chloral hydrate $(\mathrm{CH})$ treatment decreased the levels of NF- $\kappa \mathrm{B}$ activity of the RAW264.7 cells during PGN stimulation. One day after the RAW264.7 cells were co-transfected with NF- $\kappa \mathrm{B}$-luciferase- and $\beta$-galactosidase-reporter vectors by electroporation, PGN $(1 \mu \mathrm{g} / \mathrm{ml})$ or PGN $(1 \mu \mathrm{g} / \mathrm{ml})$ plus chloral hydrate $(0.25$ or $1 \mathrm{mg} / \mathrm{ml})$ was added to the medium and incubated for 6 or $12 \mathrm{~h}$. The luciferase activity of the cell extracts was measured and expressed as the fold of luciferase-induction over that of a saline-treated control $\pm \mathrm{SD}$ of three independent experiments. ${ }^{* *} \mathrm{P}<0.01$ and ${ }^{* * * *} \mathrm{P}<0.001$. RLU, relative light unit; PGN, peptidoglycan; NF- $\kappa \mathrm{B}$, nuclear factor- $\kappa \mathrm{B}$.

a significantly larger reduction in the levels of luciferase activity after $12 \mathrm{~h}$ than did the lower concentration of chloral hydrate $(0.25 \mathrm{mg} / \mathrm{ml} ; \mathrm{P}<0.01)$.

Chloral hydrate-treatment reduces the increased TLR2 expression levels in PGN-treated RAW264.7 cells. The two concentrations $(0.25$ and $1 \mathrm{mg} / \mathrm{ml})$ of chloral hydrate treatment were shown to significantly reduce the inflammatory response of the peritoneal macrophages and RAW264.7 cells following PGN-stimulation compared with that of the macrophages and RAW264.7 cells treated with PGN alone, and the effect of chloral hydrate treatment on the expression levels of the receptor for PGN, TLR2, was tested using the lowest effective concentration of chloral hydrate $(0.25 \mathrm{mg} / \mathrm{ml})$ in the RAW264.7 cells.

The cells were cultured in the IMDM supplemented with $5 \%$ heat-inactivated FBS for $12 \mathrm{~h}$ with or without PGN $(1 \mu \mathrm{g} / \mathrm{ml})$ in the presence or absence of chloral hydrate $(0.25 \mathrm{mg} / \mathrm{ml}$; Fig. 3A) and harvested, and the levels of the MFI 
A

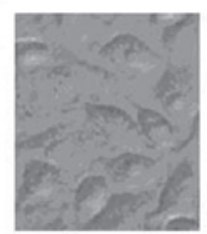

Normal

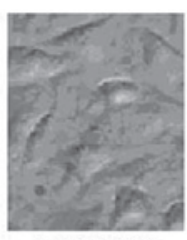

PGN+NS

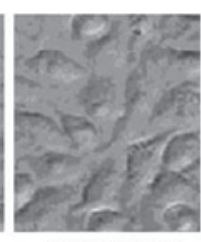

$\mathrm{PGN}+\mathrm{CH}$

C

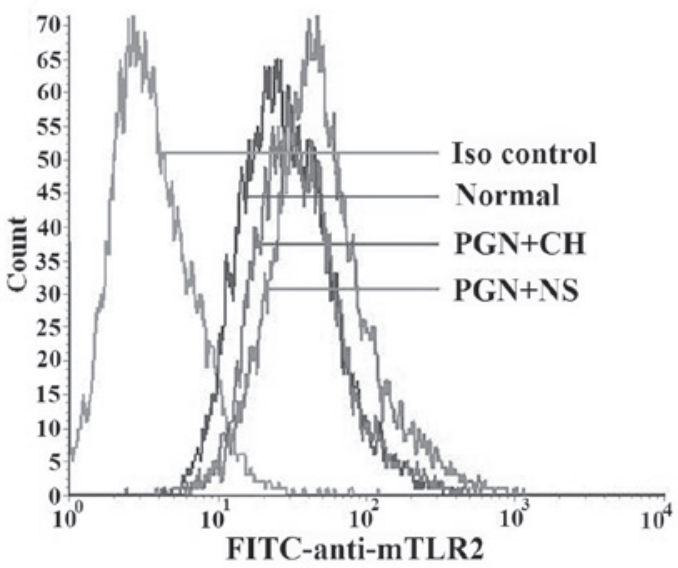

$\mathbf{E}$

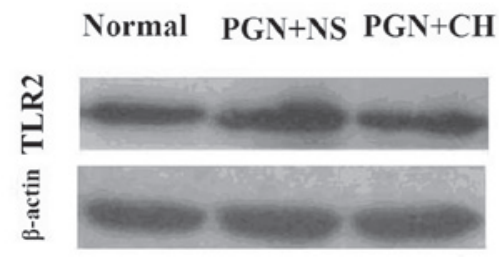

B

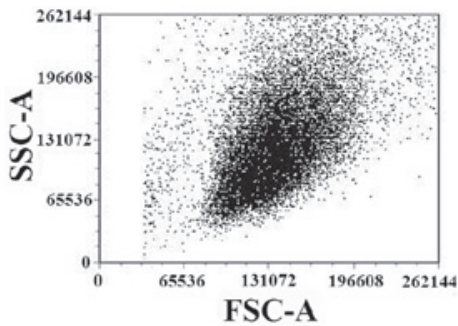

D

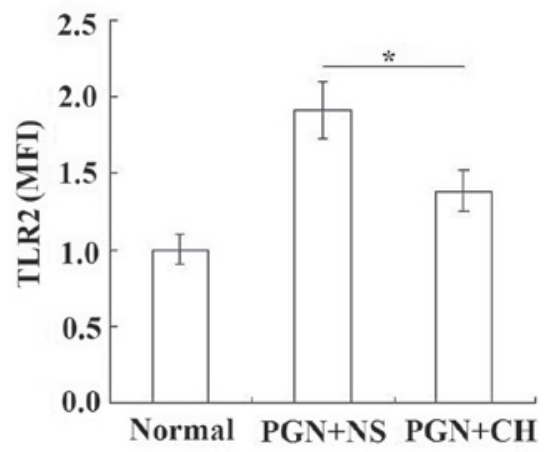

F

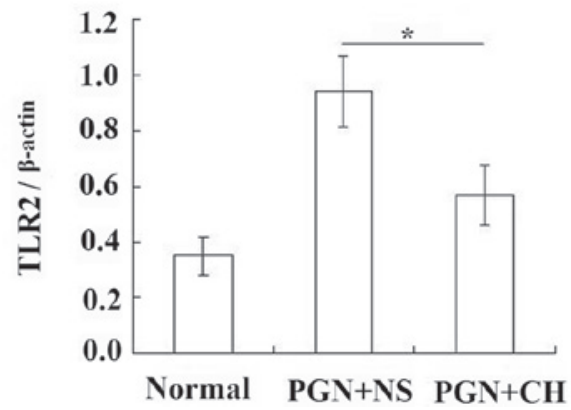

Figure 3. Chloral hydrate $(\mathrm{CH})$ treatment reduced the expression levels of TLR2 in the PGN-stimulated RAW264.7 cells. (A) The RAW 264.7 cells were cultured in IMDM supplemented with 5\% heat-inactivated FBS for $12 \mathrm{~h}$ with PGN $(1 \mu \mathrm{g} / \mathrm{ml})$ in the presence or absence of chloral hydrate $(0.25 \mathrm{mg} / \mathrm{ml})$. Flow cytometry was performed to investigate the expression levels of TLR2 in the treated RAW264.7 cells, presented as (B) dot plots and (C) histograms. The MFI derived from the fluorescence histogram was used to study the levels of the cell surface TLR2 expression. (D) The MFI was calculated as a ratio and recorded as the MFI of the TLR2 antibody divided by the MFI of the normal control (normal saline group). The semi-quantitative analysis of the extracts from the RAW264.7 cells by BandScan and the ratio of TLR2 to $\beta$-actin is shown; (E) shows a western blot of $\beta$-actin and TLR2 in the normal, PGN+NS and PGN+CH groups and (F) shows a quantitation of them. The data are expressed as the mean \pm SD of three independent experiments. "P<0.05. PGN, peptidoglycan; FITC, fluorescein isothiocyanate; TLR2, toll-like receptor 2; IMDM, Iscove's modified Dulbecco's medium; MFI, mean channel fluorescence intensity.

of TLR2 were measured. In the RAW264.7 cells stimulated by PGN $(1 \mu \mathrm{g} / \mathrm{ml})$ for $12 \mathrm{~h}$, the TLR2 expression levels were significantly increased (Fig. 3B-D) compared with those in the unstimulated cells, and the chloral hydrate treatment $(0.25 \mathrm{mg} / \mathrm{ml})$ significantly reduced the upregulation of the levels of TLR2 stimulated by PGN (P<0.05; Figs. 3B-D).

The corresponding semi-quantitative analysis of the levels of TLR 2 expression in the extracts of the RAW264.7 cells by western blotting showed a similar trend (Fig. 3E and F). This shows that if the amounts of TLR 2 signal are considered in relation to the signal of the household protein $\beta$-actin, the increase and the reduction of the TLR2 signals are not caused by cell death or variations in the number of cells in the sample.

Treatment of PGN-induced RAW264.7 cells with chloral hydrate reduces the levels of TLR2 signal transduction. Although chloral hydrate-treatment reduced the increased
TLR2 expression levels in the PGN-treated RAW264.7 cells, whether the levels of TLR2-associated signal transduction molecules, including phospho-p38 MAPK, phospho-ERK1/2, phospho-IкB $\alpha$ and phospho-Akt $(18,19)$, were reduced was unknown.

The effect of chloral hydrate on TLR2 signal transduction was investigated by western blotting, and the lower effective concentration $(0.25 \mathrm{mg} / \mathrm{ml})$ was selected to test the effect of chloral hydrate treatment on TLR2 signal transduction in RAW264.7 cells.

Following culture in IMDM supplemented with 5\% heat-inactivated FBS for $12 \mathrm{~h}$ with or without PGN $(1 \mu \mathrm{g} / \mathrm{ml})$ in the presence or absence of chloral hydrate $(0.25 \mathrm{mg} / \mathrm{ml})$, the upregulation of signal transduction of TLR2 in RAW264.7 stimulated by PGN $(1 \mu \mathrm{g} / \mathrm{ml})$ for $12 \mathrm{~h}$ was tested for significance with western blotting. The upregulation of TLR 2 signal transduction stimulated by PGN was reduced following chloral hydrate $(0.25 \mathrm{mg} / \mathrm{ml})$ treatment (Fig 4$)$. 
A

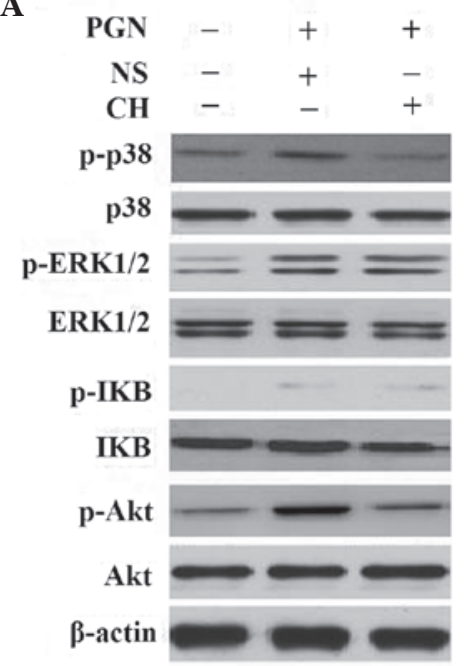

B

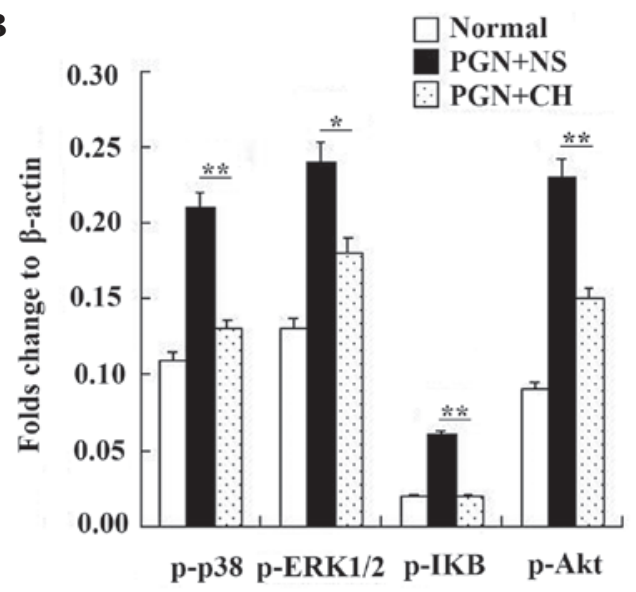

Figure 4. RAW264.7 cells were treated with PGN $(1 \mu \mathrm{g} / \mathrm{ml})$ for $12 \mathrm{~h}$ in the presence or absence of chloral hydrate $(\mathrm{CH}$; $0.25 \mathrm{mg} / \mathrm{ml})$. The cell lysates were

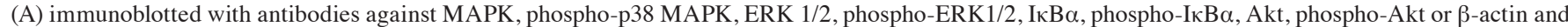
(B) semi-quantified to show the reduction in signal. The experiments were repeated three times with similar results. PGN, peptidoglycan; ERK, extracellular signal-regulated kinase; MAPK, mitogen-associated protein kinase.

\section{Discussion}

The mechanisms of bacteria-induced acute inflammation and anti-cytokines as therapeutic agents have been reevaluated. The majority of the reported studies on sepsis-associated anti-cytokine therapies have been unpromising or disappointing (22-24). Intensive investigative efforts have been made with the aim of developing novel drugs and treatment strategies for severe sepsis and acute inflammation.

The process for the development and approval of novel drugs in therapeutic programs requires a large amount of time and effort. Novel uses for traditional, old drugs may accelerate the development and application of new therapies. For example, the bisphosphonate zoledronic acid, which has been used to treat osteoporosis and similar diseases, also decreases breast cancer metastasis (25), and thalidomide, which was originally used to alleviate nausea and morning sickness, is able to treat multiple myeloma (26). The identification of the protective effects of certain anesthetics and sedatives against infection or inflammation (27-30) may yield novel insights into anti-inflammatory therapies.

As a traditional anesthetic, chloral hydrate is typically used in patients and animal models and may be administered by mouth, injection and direct placement into the intestine/small bowel. Chloral hydrate is unlike isoflurane, an inhalation agent that must be inhaled continuously and is expensive. Chloral hydrate is able to be used freely in a number of countries, but other sedatives, for example ketamine, are under strictly regulated conditions in China and are not approved for patients under 16 years old by the US Food and Drug Administration (1).

The present study in murine peritoneal macrophages showed that chloral hydrate treatment reduced the rise of the inflammatory cytokine levels induced by PGN stimulation (Fig. 1), indicating that the effect of chloral hydrate on inflammation may be attributed to the inhibition of the macrophage function. The TNF- $\alpha$ and IL-6 levels sharply increased at 6,12 and $24 \mathrm{~h}$ after the PGN-challenge. Similar studies using PGN (10 or $25 \mu \mathrm{g} / \mathrm{ml}$ ) have been performed by Shirasawa et al (31) and Wang et al (32), although they tested the levels at $24 \mathrm{~h}$ after one challenge. The treatments with different concentrations $(0.25$ and $1.0 \mathrm{mg} / \mathrm{ml})$ of chloral hydrate significantly reduced the rise of inflammatory cytokine levels at the indicated time points compared with those of the cells treated with PGN alone (Fig. 1).

In the present study, whether chloral hydrate regulates PGN-induced NF- $\kappa \mathrm{B}$-dependent gene transcription was investigated with a $\mathrm{NF}-\kappa \mathrm{B}$-dependent luciferase reporter assay in RAW264.7 cells co-transfected with a $\beta$-galactosidase control plasmid. The results revealed that chloral hydrate treatment reduces the levels of NF- $\kappa \mathrm{B}$ activity (Fig. 2). As NF- $\mathrm{B}$ plays a key role in the transcriptional regulation of proinflammatory cytokine expression, this result suggests that chloral hydrate may affect cytokine expression by influencing the activity of $\mathrm{NF}-\kappa \mathrm{B}$. After 6 and $12 \mathrm{~h}$ of PGN challenge, the respective increases of the levels of $\mathrm{NF}-\kappa \mathrm{B}$-induced luciferase activity in the RAW264.7 cells were $~ 1.5$ - and 3.5-fold compared with the basal level. A similar study using PGN (5 $\mu \mathrm{g} / \mathrm{ml})$ was performed by Ito et al (33), and they observed the same effect.

The present also study examined whether chloral hydrate modulates the PGN-induced upregulation of TLR2 expression levels. Flow cytometry was used to analyze the effect of chloral hydrate on the expression levels of TLR2 in RAW264.7 cells stimulated by PGN. The expression levels of TLR2 in the RAW264.7 cells were significantly upregulated following PGN stimulation compared with those in the untreated cells. Similar results have been demonstrated by Chen et al (16). Following the chloral hydrate treatment, the marked upregulation of the TLR2 expression levels in response to PGN exposure was significantly reduced (Fig. 3), which is consistent with the effect of chloral hydrate on the levels of NF- $\mathrm{B}$ activity and inflammatory cytokine production by RAW264.7 cells stimulated with PGN.

Having identified that the clear upregulation of TLR2 expression levels in response to PGN exposure was markedly diminished following treatment with chloral hydrate, the present 
study evaluated the effects of PGN and chloral hydrate on TLR2 signal transduction by analyzing the levels of signaling species, including p38 MAPK, ERK1/2, I $\kappa \alpha$ and Akt. In the RAW264.7 cells, PGN markedly induced the activation by phosphorylation of p38 MAPK, ERK1/2, I $\mathrm{BB} \alpha$ and Akt, but this phosphorylation was reduced by the chloral hydrate treatment (Fig. 4).

The present study showed, to the best of our knowledge, for the first time that chloral hydrate reduced the PGN-induced upregulation of the levels of NF- $\kappa \mathrm{B}$ activity and TNF- $\alpha$ and IL-6 production by macrophages in a time- and concentration-dependent manner. It was demonstrated that this reduction was associated with attenuation of the upregulation of PGN-induced-TLR2 expression and TLR2 signal transduction levels. Knowing the mechanisms of chloral hydrate treatment in inflammation provides opportunities to design novel therapeutic strategies for reducing the inflammation caused by $\mathrm{G}+$ organisms.

\section{Acknowledgements}

The authors are grateful for the support of the Natural Science Foundation of China (no. 81202346), the Natural Science Foundation of Guangdong Province (no. S2012040006216), the Zhanjiang Planning Project of Science and Technology (no. 2012C3101028/2013B01086), the Medical Scientific Research Foundation of Guangdong Province (no. B2012284) and the Doctoral Fund of Guangdong Medical College and Affiliated Hospital of Guangdong Medical College to Qingjun Pan.

\section{References}

1. Mellon RD, Simone AF and Rappaport BA: Use of anesthetic agents in neonates and young children. Anesth Analg 104: 509-520, 2007.

2. Sury MR and Fairweather K: The effect of melatonin on sedation of children undergoing magnetic resonance imaging. Br J Anaesth 97: 220-225, 2006.

3. Harrison D, Loughnan P, Manias E and Johnston L: Utilization of analgesics, sedatives, and pain scores in infants with a prolonged hospitalization: a prospective descriptive cohort study. Int J Nurs Stud 46: 624-632, 2009

4. Layangool T, Sangtawesin C, Kirawittaya T, et al: A comparison of oral chloral hydrate and sublingual midazolam sedation for echocardiogram in children. J Med Assoc Thai 91 (Suppl 3): S45-S52, 2008.

5. Liu N, Fan G, Yu B and Guo Q: Effect of slight sedation with chloral hydrate on the BOLD response of children's visual cortex: a self-control fMRI study. Chin J Med Imaging Technol 24: 1901-1904, 2008 (In Chinese).

6. Yuksel BC, Serdar SE, Tuncel A, et al:. Effect of tempol, a membrane-permeable radical scavenger, on mesenteric blood flow and organ injury in a murine cecal ligation and puncture model of septic shock. Eur Surg Res 43: 219-227, 2009.

7. Nazam Ansari M, Bhandari U, Islam F and Tripathi CD: Evaluation of antioxidant and neuroprotective effect of ethanolic extract of Embelia ribes Burm in focal cerebral ischemia/reperfusion-induced oxidative stress in rats. Fundam Clin Pharmacol 22: 305-314, 2008.

8. Uematsu M, Takasawa M, Hosoi R and Inoue O: Uncoupling of flow and metabolism by chloral hydrate: a rat in-vivo autoradiographic study. Neuroreport 20: 219-222, 2009.

9. Zhu M, Ackerman JJ and Yablonskiy DA: Body and brain temperature coupling: the critical role of cerebral blood flow. J Comp Physiol B 179: 701-710, 2009.

10. Martinbiancho JK, Carvalho PR, Trotta Ede A, et al: Evidence of safety of chloral hydrate for prolonged sedation in PICU in a tertiary teaching hospital in southern Brazil. Eur J Clin Pharmacol 65: 1253-1258, 2009.
11. Bronley-DeLancey A, McMillan DC, McMillan JM, et al: Application of cryopreserved human hepatocytes in trichloroethylene risk assessment: relative disposition of chloral hydrate to trichloroacetate and trichloroethanol. Environ Health Perspect 114: 1237-1242, 2006.

12. Merdink JL, Robison LM, Stevens DK, et al: Kinetics of chloral hydrate and its metabolites in male human volunteers. Toxicology 245: 130-140, 2008.

13. Pan Q, Liu Y, Zheng J, et al: Protective effect of chloral hydrate against lipopolysaccharide/D-galactosamine-induced acute lethal liver injury and zymosan-induced peritonitis in mice. Int Immunopharmacol 10: 967-977, 2010.

14. Chang S, A Dolganiuc and G Szabo: Toll-like receptors 1 and 6 are involved in TLR2-mediated macrophage activation by hepatitis C virus core and NS3 proteins. J Leukoc Biol 82: 479-487, 2007.

15. Merkel GJ and Scofield BA: Characterization of a monoclonal antibody that binds to an epitope on soluble bacterial peptidoglycan fragments. Clin Diagn Lab Immunol 8: 647-651, 2001.

16. Chen BC, Kang JC, Lu YT, et al: Racl regulates peptidoglycan-induced nuclear factor-kappaB activation and cyclooxygenase-2 expression in RAW 264.7 macrophages by activating the phosphatidylinositol 3-kinase/Akt pathway. Mol Immunol 46: 1179-1188, 2009.

17. Lin HY, Tang CH, Chen JH, et al: Peptidoglycan induces interleukin-6 expression through the TLR2 receptor, JNK, c-Jun, and AP-1 pathways in microglia. J Cell Physiol 226: 1573-1582, 2011.

18. Li X, Jiang S and Tapping RI: Toll-like receptor signaling in cell proliferation and survival. Cytokine 49: 1-9, 2010.

19. Lee GL, Chang YW, Wu JY, et al: TLR 2 induces vascular smooth muscle cell migration through cAMP response element-binding protein-mediated interleukin- 6 production. Arterioscler Thromb Vasc Biol 32: 2751-2760, 2012.

20. Yin MZ, Li SP, Yuan L and Dai HL: Separation, cultivation and identification of mouse peritoneal macrophages. Med J Wuhan Univ 27: 203-205, 2006 (In Chinese).

21. Vabulas RM, Ahmad-Nejad P, Ghose S, et al: HSP70 as endogenous stimulus of the Toll/interleukin-1 receptor signal pathway. J Biol Chem 277: 15107-15112, 2002.

22. Hall MW and Muszynski JA: Immune modulation in sepsis. J Pediatr Infect Dis 4: 127-136, 2009.

23. Zeni F, Freeman B and Natanson C: Anti-inflammatory therapies to treat sepsis and septic shock: a reassessment. Crit Care Med 25: 1095-1100, 1997

24. Ratsimandresy RA, Rappaport J and Zagury JF: Anti-cytokine therapeutics: history and update. Curr Pharm Des 15: 1998-2025, 2009.

25. Coleman R and Gnant M: New results from the use of bisphosphonates in cancer patients. Curr Opin Support Palliat Care 3: 213-218, 2009.

26. Cavo M, Di Raimondo F, Zamagni E, et al: Short-term thalidomide incorporated into double autologous stem-cell transplantation improves outcomes in comparison with double autotransplantation for multiple myeloma. J Clin Oncol 27: 5001-5007, 2009.

27. Plachinta RV, Hayes JK, Cerilli LA and Rich GF: Isoflurane pretreatment inhibits lipopolysaccharide-induced inflammation in rats. Anesthesiology 98: 89-95, 2003.

28. Gallos G, Jones DR, Nasr SH, et al: Local anesthetics reduce mortality and protect against renal and hepatic dysfunction in murine septic peritonitis. Anesthesiology 101: 902-911, 2004.

29. Fuentes JM, Talamini MA, Fulton WB, et al: General anesthesia delays the inflammatory response and increases survival for mice with endotoxic shock. Clin Vaccine Immunol 13: 281-288, 2006.

30. de Klaver MJ, Manning L, Palmer LA and Rich GF: Isoflurane pretreatment inhibits cytokine-induced cell death in cultured rat smooth muscle cells and human endothelial cells. Anesthesiology 97: 24-32, 2002.

31. Shirasawa S, Sugiyama S, Baba I, et al: Dermatitis due to epiregulin deficiency and a critical role of epiregulin in immune-related responses of keratinocyte and macrophage. Proc Natl Acad Sci USA 101: 13921-13926, 2004.

32. Wang N, Satoskar A, Faubion W, et al: The cell surface receptor SLAM controls T cell and macrophage functions. J Exp Med 199: 1255-1264, 2004.

33. Ito Y, Kawamura I, Kohda C, et al: Seeligeriolysin O, a protein toxin of Listeria seeligeri, stimulates macrophage cytokine production via Toll-like receptors in a profile different from that induced by other bacterial ligands. Int Immunol 17: 1597-1606, 2005. 